\title{
$2 \mathfrak{D} \mathfrak{x} \mathfrak{e} \mathfrak{e}$
}

Saft jeber Bienenlebrer beobadtet eite von andere verfdiedente Methode in ber Befandlung der Bienten, die er nady a!len iffen Lumftánden Eefannt zu machen und fut verbreiten fudst. (Fs fiuts Daber fo viele Bienenbúdher gefdhrieben worden, Dak $\mathfrak{w o b l}$ fo leidgt Eein $B$ ienenfreund im Stande ift, fith Die gan:e 2unjafl Der fel= ben anjufdaffen, um Durd) Deren Schillfe

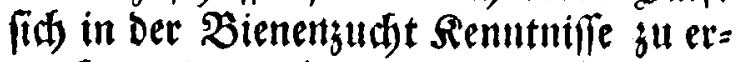
werben ober, Die er bereitz bat, zu erweiten. Da eB̉ nun bey ber $\mathfrak{B}$ ienen= zutht atif bie natúrlids)fe. und einfadhfe Bebandlung ber Bienen antommt, unb eit nut moglidgft geringer Rofienauf wand Damit vetEnúpft fenn muß̧, wenn er an= Dere betrádbtlidge Bortheile genvåbren foll; fo habe id) aus ben beften Sdhriften úber biefen Gegenftand das Zwedémápig = fee ausgefoben und bier bufammengetra= gen, wodurd) Der Kiebraber Der Bienen= gucht in Stand gefestet wird, feine Bies nen auf bie leidftefte uno bequemfte 2 Seife 3u Gefandeln. Berlin im Minit 1794 .

Der $\mathfrak{Z e r f a f f e r}$. 